\title{
Points mechanisms and rewards programs
}

\author{
Emil Temnyalov*
}

October 16, 2018

\begin{abstract}
I study points programs, such as frequent flyer and other rewards programs, as a revenue management tool. I develop a two-period contracting model where a capacityconstrained firm faces consumers who privately learn their valuations over time. The firm cannot commit to long-term contracts, but it can commit to allocate any unsold capacity through a points program. This points scheme creates an endogenous and type-dependent outside option for consumers, which generates novel incentives in the firm's pricing problem. It induces the firm to screen less ex interim, and to offer lower equilibrium prices, reversing the intuition of demand cannibalization.
\end{abstract}

Keywords: Rewards programs, loyalty programs, dynamic contracting, revenue management, limited commitment, points mechanisms.

JEL: D21, D42, D61, D86, L10, L93

\footnotetext{
*University of Technology Sydney, Economics Department, Sydney, NSW 2007, Australia. Email: emil.temnyalov@uts.edu.au.

I thank Editor Casadesus-Masanell, an anonymous Co-Editor, and two anonymous referees - their comments greatly improved the paper. For helpful comments I thank David Besanko, Kevin Bryan, Jeff Ely, Keiichi Kawai, Anton Kolotilin, Mara Lederman, Jorge Lemus, Bill Rogerson, Asher Wolinsky and John Wooders, as well as audiences and discussants at IIOC 2015, AETW 2016, the Econometric Society Asia Meeting 2016, the UQ IO-theory workshop 2016, Drexel University, Monash University, Northwestern University, University of Melbourne, UNSW, University of Technology Sydney, University of Toronto, and University of Washington Bothell. I have also benefitted from the expertise of Ravindra Bhagwanani of Global Flight.
} 


\section{Introduction}

Points programs are schemes where a firm creates a currency (e.g. frequent flyer miles or hotel guest points), designed to influence consumers' choices and incentivize particular behavior. Such points are typically either bundled with the purchase of another good (e.g. a flight or a hotel stay), or sold separately (e.g. through a credit card issuer or a bank). Consumers accumulate this currency over time and eventually can redeem it for goods. Points programs are thus a type of indirect allocation mechanism through which the firm allocates goods to some types of customers. The economics literature on reward programs has generally focused on their role as a tool to build customer loyalty, or as a way for the firm to introduce switching costs into the consumer's choices. In this paper I focus on a different, complementary function of rewards programs as a way to implement dynamic pricing, where the firm offers consumers the option to participate in a points program and to obtain the good through it with some probability.

Consider, for example, frequent flyer programs, one of the most well known types of such points mechanisms. In practice industry experts often describe such programs as a tool for airlines to sell "distressed inventory," i.e. residual unsold capacity. 1 In recent decades such programs have become one of the most significant drivers of profitability in the airline industry, and also account for a significant share of seats. ${ }^{2}$ Moreover, there is now a very sizable market for airline miles: a majority of miles are in fact not earned by customers who fly with an airline, but sold to banks, who pre-purchase them from the airline and award them to their own customers as promotional incentives.$^{3}$ On average consumers collect points over a period of 30 months before they redeem them for an award seat, which suggests that points programs also introduce a novel dynamic aspect into the firm's pricing problem, in addition to the usual revenue management question of how to set prices over time $4^{4}$ In the airline market, as well as in other industries that fit my model, such as hotels and car rentals, the firm determines the rate at which points are issued, it sets the prices that it charges for redemptions in terms of points, and it chooses

\footnotetext{
${ }^{1}$ See for example "Persuasive Perks: The World of Loyalty Programs" (CBC, May 26 2016); "Exploring the leverage in airline loyalty" (Thooz, Jan 22 2015); "The Information Company" (Oracle report, 2008).

${ }^{2}$ See for example "Airlines Make More Money Selling Miles Than Seats" (Bloomberg, March 31 2017). In 2007 financial analysts estimated the value of United's MileagePlus program to be approximately $\$ 7.5$ billion, and concluded that the loyalty program, if it operated as a stand-alone business, could be worth more than United itself, which at the time had a market value of $\$ 5.45$ billion. See for example "Getting mileage out of frequent fliers" (Chicago Tribune, July 24 2007). MileagePlus had annual revenues of $\$ 3$ billion in 2010, according to IdeaWorks: "Loyalty by the Billions" (IdeaWorks, September 12 2011). At American Airlines, on average $8 \%$ of seats are now taken up by consumers who redeem miles, rather than buy a ticket.

${ }^{3}$ Industry expert Ravindra Bhagwanani of Global Flight estimates that, for a typical major U.S. airline, approximately $30-45 \%$ of miles issued are awarded to the airline's own flyers and $5-10 \%$ to partner airlines customers, $40-55 \%$ are sold to credit card issuers, $3-8 \%$ to hotel programs, $2-5 \%$ to car rental companies, and $2-10 \%$ to retail and other partners.

"The Price of Loyalty" (IATA special report, August 1 2012).
} 
how much capacity to make available for such redemptions. Points mechanisms can therefore be a valuable revenue management and dynamic price discrimination tool.

A natural question in this setting is how the firm can use a points program in conjunction with its usual pricing mechanism, to maximize revenues. Consider the pricing problem of a capacityconstrained firm, as in the examples of the airline and hotel industry. If the firm anticipates that demand in some particular period is low, it may optimally decide to set prices such that it does not sell all of its capacity. The firm could in this case offer a points program and allow some of its customers who participate in this program to redeem their points for some of the residual unsold capacity. However, this introduces the possibility of demand cannibalization: sophisticated consumers should anticipate that they may obtain the good through the points program, which will affect the price they would be willing to pay for the good outside of this program. The terms of the points program thus clearly affect the firm's pricing decisions. I show that this intuition for demand cannibalization is in fact incomplete: although at any given price the revenue-generating demand for the good indeed decreases when the firm allows consumers to redeem their points for the good, the firm's optimal price is in fact lower when it offers this additional channel to obtain the good, and moreover in equilibrium the firm sells more units, in addition to whatever residual capacity is allocated through the points program. The firm can use this as a form of endogenous pricing commitment and extract larger revenue overall, even in the absence of competition, i.e. in a setting where loyalty and switching costs cannot play any role.

I develop a screening model of points programs, to explain why such programs are profitable and how firms can design them optimally. I consider a model where a seller, the firm (e.g. an airline), has a fixed capacity of a good to sell to a population of buyers, the consumers. The seller and the buyers interact over two periods: period 1 is an ex ante contracting stage; period 2 is a standard spot market where the seller offers a mechanism to allocate its capacity among the buyers. Consumers learn their willingness to pay over time: in period 1 they privately learn their type, a noisy signal of their valuation for the good, whereas in period 2 they privately learn their exact valuations; the seller only knows the distribution of buyers' valuations and types, as in the standard mechanism design problem. In this setting, I study the problem of dynamic contracting with limited commitment: suppose that in period 2 the seller has full commitment regarding the contract it offers at that stage, but it cannot commit to it ex ante, in period 1. Instead, in period 1 the seller can offer a points program to consumers, whereby it commits to allocate any unsold goods in period 2 among members of the program. How does the ability to offer such a scheme affect the optimal mechanism in the later stage, and how should the seller sell access to this scheme? 
In my model the points scheme provides the seller with one more tool to allocate its capacity dynamically, in addition to the mechanism that it can offer in period 2. This is a natural way to introduce limited commitment into a sequential screening model, which is motivated by the many examples of such points schemes in practice, such as frequent flyer and hotel programs. This setting falls inbetween two alternative canonical assumptions regarding commitment: in the sequential screening literature the seller is generally assumed to have full commitment, and hence the ability to offer a two-period mechanism; in the literature on dynamic mechanism design without commitment the seller is assumed to have full commitment within each period, but no commitment at all regarding future periods. I characterize the seller's revenue from the optimal points mechanism, and find that it is larger than that in the optimal static mechanism, but smaller than that in the optimal dynamic mechanism with full commitment. That is, the points program provides the seller with a valuable type of commitment, which it can use to partially contract with future buyers ex ante and increase its overall revenue. On the other hand, this type of program is not as valuable as the dynamic mechanism that the seller would offer if it could fully commit to all future contracts ex ante.

The seller's mechanism in period 2 has to be sequentially optimal, since the seller cannot commit to it ex ante. The points program introduces an endogenous and type-dependent outside option for consumers at this point: they can obtain the good through the spot contract that the seller offers at that stage, or through the points program. Redemptions through the points program generally involve rationing, since any residual capacity is allocated among all members of the points program. The consumer's trade-off is whether to obtain the good with certainty at the seller's posted price, or with some probability through the points program. I show that this trade-off separates consumer types monotonically: in equilibrium in period 2 high types buy at the posted price, while low types choose the points lottery. The price that the seller sets to induce such an allocation has to leave some rents to the high types, in addition to the usual information rents that they receive due to private information. Hence by offering a points program ex ante, the seller seemingly cannibalizes some of its demand in period 2 .

Importantly, the optimal price is in fact lower than the optimal price in the standard static monopolistic screening mechanism, and moreover the marginal buyer type is lower than in the static mechanism. In other words, if the seller sells points in period 1 it will subsequently offer a contract whereby it sells more units in the spot market, at a lower price, and in addition it will give away any remaining unsold capacity. The sequentially optimal contract in period 2 is thus more efficient than the static benchmark. Intuitively, in the optimal points mechanism the seller sets a lower price because it has an additional incentive to increase the quantity sold that is not present in the usual monopolistic screening trade-off. When deciding whether to sell an extra unit on the margin, the seller takes into account the typical effects this will have: the 
additional revenue from the marginal unit, and the necessary decrease in price for infra-marginal units. But it now also faces an additional consideration: if it sells an extra unit, it induces less generous rationing in the points lottery, i.e. it decreases the equilibrium probability that a consumer who takes the lottery will obtain a unit. This implies that the outside option of each type decreases, and so the price that the seller can charge the marginal buyer type increases $5^{5}$

While this suggests at first that the adoption of a points program is costly, because it leads to some demand cannibalization and induces equilibrium prices that are below the optimal static screening prices, the seller does better with the points mechanism overall. This is because, by offering a points program, the seller reduces its incentive to restrict the quantity it sells in the period 2 spot market, i.e. it screens consumers less at the stage where they have private information about their values. This reduces the typical inefficiency that arises in a monopolistic market and increases the consumers' interim surplus in period 2. However, the seller can capture some of this surplus in period 1, through the price it sets for participation in the points program. Total surplus in the points mechanism is larger than in the optimal static mechanism, and the seller can capture this incremental gain in surplus in period 1, as the price for participation in the points program captures some of the consumer's expected interim surplus, relative to its surplus if it does not participate in the points program. Hence the seller benefits from the ability to offer a points program, as it shifts the incentives to screen consumers more on period 1 rather than period 2 .

\section{Related literature}

I consider a two-period model where consumption happens in the second stage, while the first stage is only a contracting device. The model is thus most closely related to the literature on sequential screening, including the seminal paper by Courty and Li (2000). In their setting the firm has full commitment power when it contracts in the first stage, and the optimal contract is a refund contract that depends on the buyer's type in period 2. Akan, Ata and Dana (2015) generalize this model and extend the intuition to a setting where consumers learn about their types at different times. In contrast, I study the case where the firm cannot sell long-term contracts ex ante, and has fixed capacity. Deb and Said (2014) weaken some of the commitment assumptions of the sequential screening literature. In their model consumers arrive in two cohorts, and when the firm sells contracts to the first cohort it cannot commit to the prices that it will offer in the second cohort. I further weaken the firm's commitment power,

\footnotetext{
${ }^{5}$ Notice that if the firm could commit to a period 2 mechanism ex ante, this consideration would be absent. In the optimal mechanism with commitment the firm fully internalizes the effect of the period 2 allocation.
} 
since it cannot offer a long-term contract in the first stage.

Hua (2007) studies an auction where the seller has the ability to contract with one uninformed buyer prior to the auction. The optimal contract in this setting has several similarities to the optimal mechanism in my setting: it induces less rent-seeking by the auctioneer in the auction stage, it increases the probability of trade by favoring the contracted buyer, and it may increase total surplus, similar to the effect of ex ante contracting that I consider.

This paper is also related to the large literature on revenue management with strategic buyers, including Aviv and Pazgal (2008), Jerath, Netessine and Veeraraghavan (2010) and Board and Skrzypacz (2016), among others. Hörner and Samuelson (2011) study the problem of a monopolist who posts prices over time in order to sell her inventory before a deadline, where the seller lacks commitment. Dilme and Li (2016) also study revenue management in a dynamic model with no commitment: a seller has some fixed number of units to sell before a deadline, buyers arrive over time and can strategically time their purchases, and the seller cannot commit to what prices it will offer in the future. Öry (2016) studies a dynamic pricing model where a seller can offer targeted sales over time, which induces lower regular prices due to lack of commitment. Dana and Williams (2018) show that inventory controls (where firms commit to unit-sales limits) allow oligopolistic firms to implement a form of dynamic price discrimination, which would otherwise only arise in a monopoly. My results also share some intuitive similarity with models of monopoly pricing with demand uncertainty, such as in Nocke and Peitz (2007).

A recent literature in management considers the question of how a firm could exploit unsold inventory to incentivize customer purchases. Kim, Shi and Srinivasan (2001) study the design of reward programs and their effect on competition in a setting where consumers differ in their ability to participate in rewards programs and in their price sensitivity. Kim, Shi and Srinivasan (2004) study the role of rewards programs in capacity management with competing firms. I consider a setting with a single firm and no aggregate demand uncertainty, and show that rewards programs can also be a valuable revenue management tool, even absent capacity management and competitive effects.

This paper also relates to the literature on endogenous switching costs in a horizontally differentiated market, such as in Fudenberg and Tirole (2000), Caminal and Matutes (1990), and the comprehensive overview in Stole (2007). This literature studies a two-period oligopolistic model where competing firms sell a product in both periods and the firm benefits either from the ability to write long term contracts that lock consumers in, or from the ability to learn about a buyer's unchanging preferences. In contrast, I focus on a monopolistic setting where there is no scope for switching costs to play any role, and I study the dynamic price discrimination aspect of points and loyalty programs. 
More generally, the paper relates to the literature on dynamic mechanism design, including Baron and Besanko (1984), Pavan, Segal and Toikka (2014), Bergemann and Välimäki (2010), Battaglini and Lamba (2015), Ata and Dana (2015), Garrett (2016), Garrett (2017), Ely, Garrett and Hinnosaar (2017), Gershkov, Moldovanu and Strack (2018). In contrast to the above papers, which feature dynamic information, Said (2012) and Board and Skrzypacz (2016) study models with a dynamic population of agents with fixed private information, where the designer can commit to a mechanism. Skreta (2006) considers optimal dynamic mechanisms in a model where the seller has no commitment, and shows that posted prices maximize revenue in this setting, while Skreta (2015) analyzes sequential auction design without commitment.

A smaller empirical literature also studies the economics of frequent flyer programs in the airline industry, including Borenstein (1992), Borenstein and Rose (1994), Lederman (2007) and Lederman (2008).

\section{Model}

Setup. A seller (or firm) faces a measure 1 of buyers (or consumers) with unit demand for a good. The seller and buyers interact over two periods, $\tau \in\{1,2\}$, where period 1 is an ex ante contracting stage and period 2 is a spot market for the good. Consumption happens only in period 2. The seller has capacity $k \in(0,1)$ and marginal cost normalized to 0 .

Information. I consider a standard two-period information structure: suppose that in period 1 buyers have some noisy private information about the distribution of their valuations for the good in period 2, and in period 2 each buyer privately learns her exact valuation (i.e. her consumption utility) for the good, $v$, which is distributed according to some CDF with support normalized to $[0,1]$. In particular, in period 1 buyer $i$ has type $t_{i}=t_{1}$ with probability $\mu$, or $t_{i}=t_{2}$ with probability $1-\mu$. Each type $t_{i}$ in period 1 corresponds to a distribution over the buyers' valuations' realized in period 2: type $t_{1}$ has $v$ drawn from some distribution $F_{1}$, while type $t_{2}$ has $v$ drawn from some distribution $F_{2}$. This environment has two main features: first, buyers privately learn their valuations over time; and second, they have some noisy information in period 1 , with types corresponding to different distributions of valuations in period $26^{6}$ The information structure is common knowledge among the agents.

\footnotetext{
${ }^{6}$ One could also model period 1 heterogeneity as a continuum of types $t_{i} \in[0,1]$ which correspond to different period 2 distributions $F_{i}$ over $v$, with a stochastic order over $\left\{F_{i}\right\}$. However, given the subsequent assumption I will make about the kinds of contracts the seller can offer in period 1, this additional machinery plays no role in this setting. Hence for simplicity I focus on the case where period 1 types are binary.
} 
Contracts. I consider a contracting environment where the seller can sell the good in a spot market at $\tau=2$, and in addition at $\tau=1$ it can offer a points program, whereby it commits to allocate any unsold capacity in period 2 to buyers who participate in the points program in period 1. This program is a particular ex ante contract with limited dynamic commitment, and is the main focus of this paper. At $\tau=1$ the seller sets a fee $q$ for membership in the points program, and at $\tau=2$ it offers a contract in the spot market, depending on the history of agents' actions in period 1.

Buyer $i$ 's strategy consists of

$$
\begin{array}{r}
a_{i}\left(t_{i}, q\right) \in\{\text { participate, } \text { not }\} \text { at } \tau=1, \\
b_{i}\left(v, p, a_{i}\right) \in\{\text { buy, not }\} \text { at } \tau=2 .
\end{array}
$$

That is, buyer $i$ chooses whether to participate or not in the points program, as a function of its type $t_{i}$ and the fee $q$, and whether to purchase a unit of the good in the spot market, as a function of its realized valuation $v$, the price it faces, and the history of its period 1 participation..$^{7}$

Because the seller faces a continuum of infinitesimal buyers, with no aggregate uncertainty, it is without loss of generality to restrict attention to posted price mechanisms in the spot market at $\tau=2$. Hence the seller's strategy consists of:

$$
\begin{aligned}
q \text { at } \tau & =1, \\
p(a) \text { at } \tau & =2 .
\end{aligned}
$$

That is, the seller designs a points mechanism, with a membership fee $q$ chosen in period 1 , and spot prices $p(a)$ chosen in period 2 , depending on the history of play $a=\cup_{i} a_{i}$. This contracting environment features limited commitment for the seller: at $\tau=2$ it has full commitment within that period, but at $\tau=1$ it cannot commit to what prices and allocations it will offer at $\tau=2$. That is, there is no direct interdependence between $q$ and $p(\cdot)$.

This form of limited commitment is motivated by examples of such points programs offered in practice. Airlines use rewards or loyalty programs which allow consumers to redeem their

\footnotetext{
${ }^{7}$ In practice consumers may make purchase decisions dynamically: in an airline market at any point in time the consumer can buy a seat at some price, or try to obtain it through the airline's points program, where it is typically only available with some probability. Hence if the consumer cannot find a seat through the points program, she may still purchase a ticket in the spot market in the future, or wait for a seat to become available (with some probability) in the points program. I model this in a stylized way - a static game where consumers simultaneously decide whether to purchase a unit or take the lottery. While this does not explicitly capture the timing dimension of purchases, it is a realistic and simple way to model the consumer's main trade-off. Moreover, the static model fits some examples very well - for instance business class upgrades allocated to elite status flyers just before a flight.
} 
frequent flyer miles for seats; such seats are released to members of the programs according to an inventory management algorithm, which determines how many seats to release over time, with unsold seats typically released close to the date of the flight. As another example, airlines also use points programs to allocate unsold business class seats among loyalty program members with elite status. Analogous reward programs and inventory management algorithms are also used by hotels, and can be used in other industries where capacity-constrained firms sell to consumers with dynamic valuations.

Equilibrium. I focus on the equilibrium of this game where type $t_{1}$ participates in period 1 , whereas type $t_{2}$ does not - this is the most interesting case, since period 1 heterogeneity interacts with the period 2 incentives of the seller. My results implicitly also cover the case where neither type participates in period 1 (which collapses to the canonical static screening model), and the case where both types participate in period 1 (which mimics the case with no heterogeneity in period 1 , i.e. as if $\mu=1$ ). This model can also be interpreted as a setting with dynamic privately known arrival times and valuations, where buyers arrive at $\tau=1$ with probability $\mu$ and subsequently have valuations $v$ drawn from $F_{1}$, or buyers arrive at $\tau=2$ with probability $1-\mu$ and have valuations $v$ drawn from $\left.F_{2}\right]^{8}$ The results in this paper apply to both interpretations.

Timeline. To summarize, at $\tau=1$ : (i) buyers privately learn $t_{i} \in\left\{t_{1}, t_{2}\right\}$; (ii) the seller offers a points program with fee $q$; (iii) buyers decide whether to participate in the points program or not; at $\tau=2$ : (i) each buyer privately realizes her value $v \sim F_{i}$; (ii) the seller observes the history of period 1 actions, updates its beliefs about the distributions of values, and offers posted prices for the good; (iii) buyers simultaneously decide whether to purchase a unit at the posted price or not; any unsold capacity is allocated among consumers who participated in the points program at $\tau=1$ and have not bought a unit at $\tau=2$.

In this model period 1 represents the period when the seller sets the terms of its points scheme (e.g. an airline sets the earning and redemption rates for its frequent flyer program) and the price to participate (e.g. the implicit price of frequent flyer miles that is bundled into the price of past purchased tickets), while period 2 represents the market for the good itself (e.g. the market for some airline route on a specific date), where consumers have more precise private information about their willingness to pay. One could also interpret this setting as a reduced form model of

\footnotetext{
${ }^{8}$ In this interpretation, the seller can interact with type $t_{1}$ at $\tau=1$, but not with type $t_{2}$, for example because the seller has previously interacted with type $t_{1}$ and not with type $t_{2}$, as in a repeated game where consumers can purchase from the seller over different periods, and past purchases are bundled with participation in the points program.
} 
a repeated contracting game, where the seller serves overlapping cohorts of buyers over time, and the purchase in each period bundles together a unit of the good and the participation in a points program that will allocate future unsold capacity, as is the case in the hotel and airline examples.

\section{Analysis}

\subsection{The optimal points mechanism}

Consider the equilibrium of the game where all type $t_{1}$ buyers participate in the points program at $\tau=1$, while type $t_{2}$ do not. The sequentially optimal contract offered at $\tau=2$ is a posted price mechanism, $p(a)$, conditional on the history of play. At $\tau=2$ there are two cases, depending on whether buyers participate in the points program at $\tau=1$ or not, and in each case the seller updates its beliefs about the distribution of valuations and sets prices accordingly. To simplify the notation I denote the prices by $p_{1} \equiv p\left(a_{i}=\right.$ participate $)$ and $p_{2} \equiv p\left(a_{i}=n o t\right)$, since in equilibrium type $t_{1}$ participates, while type $t_{2}$ does not; note that prices themselves depend on only on period 1 actions, not types.

The value of participating in the points program is determined endogenously, depending on the sequentially optimal prices that the seller sets at $\tau=2$ in equilibrium. Given any prices $\left(p_{1}, p_{2}\right)$ and the resulting allocation at $\tau=2$, a type $t_{1}$ consumer has an endogenous outside option, to obtain the good with some probability through the points program. This probability depends on the seller's capacity and on the measure of buyers who buy a unit of the good. Notice that for any posted price $p_{i}$, there exists some marginal cutoff valuation, denoted $\bar{v}_{i}$, at which a buyer is indifferent between buying at the posted price and taking their outside option. A buyer of type $t_{i}$ with value $v_{i}>\bar{v}_{i}$ strictly prefers to buy a unit at the posted price, whereas one with value $v_{i}<\bar{v}_{i}$ strictly prefers the outside option. The following lemma expresses type $t_{1}$ 's probability of receiving a unit from the points program as a function of these marginal cutoff valuations, and then characterizes the seller's objective at $\tau=2$ as a function of the marginal buyer types, rather than prices.

Lemma 1. Let

$$
H\left(\bar{v}_{1}, \bar{v}_{2}\right) \equiv \frac{k-\mu\left[1-F_{1}\left(\bar{v}_{1}\right)\right]-(1-\mu)\left[1-F_{2}\left(\bar{v}_{2}\right)\right]}{\mu F_{1}\left(\bar{v}_{1}\right)}
$$

denote a type $t_{1}$ buyer's endogenous probability of receiving a unit from the points program, when the marginal buyer types are $\bar{v}_{1}, \bar{v}_{2}$. 
Then the seller's problem at $\tau=2$ can be written as:

$$
\max _{\bar{v}_{1}, \bar{v}_{2}} \quad \bar{v}_{1}\left[1-H\left(\bar{v}_{1}, \bar{v}_{2}\right)\right]\left[1-F_{1}\left(\bar{v}_{1}\right)\right] \mu \quad+\quad \bar{v}_{2}\left[1-F_{2}\left(\bar{v}_{2}\right)\right](1-\mu)
$$

$H\left(\bar{v}_{1}, \bar{v}_{2}\right)$ is determined endogenously in equilibrium, depending on the buyers' decisions whether to buy a unit at the posted price or not. In equilibrium it must be equal to the seller's residual capacity, divided by the measure of type $t_{1}$ buyers who take the outside option, conditional on the $t_{1}$ buyers participating in the points program at $\tau=1$. This endogenous outside option changes the buyer's purchase decision and the seller's pricing problem, relative to the usual monopolistic pricing problem with exogenous outside options, and will be reflected in the regularity condition imposed on the distribution of values, discussed further below.

The lemma also expresses the seller's objective in terms of allocations rather than prices. The seller's problem at $\tau=2$ is to choose prices $p_{1}, p_{2}$ to maximize revenue, subject to the constraints imposed by the buyers' outside options. In particular, type $t_{2}$ 's outside option is 0 , so a buyer of type $t_{2}$ buys a unit at price $p_{2}$ if and only if $v_{2} \geq p_{2}$. Hence the marginal cutoff valuation for a type $t_{2}$ buyer is

$$
p_{2}=\bar{v}_{2}
$$

In contrast, a type $t_{1}$ buyer has the option to obtain a unit from the points program, with probability $H\left(\bar{v}_{1}, \bar{v}_{2}\right)$ defined above. In equilibrium this endogenous probability must be consistent with the seller's posted prices, so we can also relate $\bar{v}_{1}$ and $p_{1}$. In particular, a type $t_{1}$ buyer with value $v_{1}$ will buy a unit at price $p_{1}$ if and only if $v_{1}-p_{1} \geq v_{1} \cdot H\left(\bar{v}_{1}, \bar{v}_{2}\right)$. Hence the marginal cutoff valuation for a type $t_{1}$ buyer is given by

$$
p_{1}=\bar{v}_{1}\left[1-H\left(\bar{v}_{1}, \bar{v}_{2}\right)\right]
$$

Figure 1 provides a graphical representation of how the $t_{1}$ cutoff valuation is determined. The marginal buyer valuation $\bar{v}_{1}$ is a fixed point in this figure, for a given $\bar{v}_{2}$ : at any posted price $p_{1}$, there is a unique cutoff $\bar{v}_{1}$ such that type $\bar{v}_{1}$ is indifferent between buying or taking the outside option, whose value itself depends on $\bar{v}_{1}$, reflected in the slope of the dashed line. The figure shows two candidate prices, $p_{1}$ (in black) and $p_{1}^{\prime}$ (in red), and the corresponding marginal types, outside options, and payoffs that they induce. The seller's problem is then to maximize over the space of allocations consistent with the outside options.

To guarantee the existence and uniqueness of an optimal mechanism, I impose the following modified regularity conditions on the distributions of values, $F_{1}$ and $F_{2}$.

Assumption 1. Assume that there exist unique $\left(\hat{v}_{1}, \hat{v}_{2}\right)$, with $\hat{v}_{1} \leq \hat{v}_{2}$, such that the value 


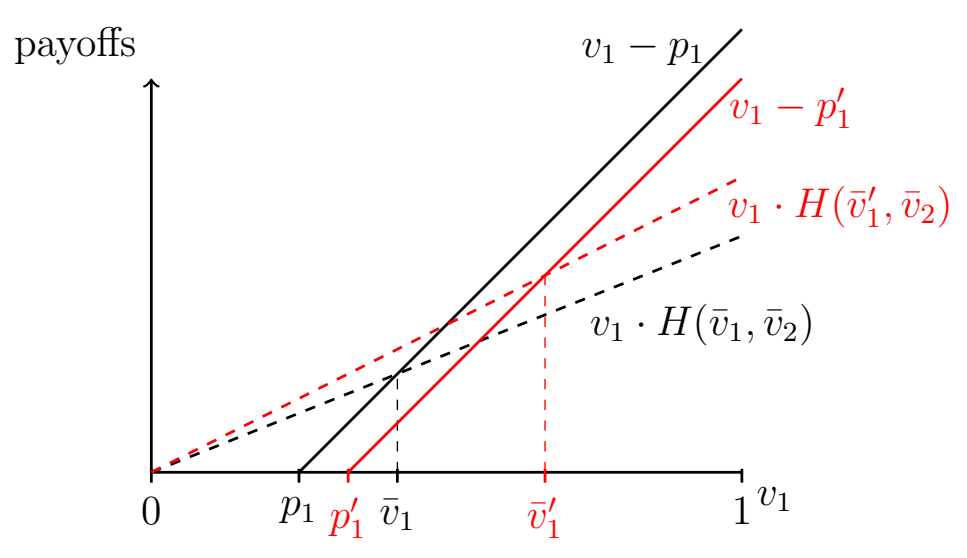

Figure 1: The cutoff type $\bar{v}_{1}$ as a fixed point.

distributions $F_{1}$ and $F_{2}$ satisfy the joint modified regularity condition:

$$
\begin{aligned}
& \hat{v}_{1}=\frac{\left[1-F_{1}\left(\hat{v}_{1}\right)\right] F_{1}\left(\hat{v}_{1}\right)}{F_{1}^{\prime}\left(\hat{v}_{1}\right)} \\
& \hat{v}_{2}=\frac{1-F_{2}\left(\hat{v}_{2}\right)}{F_{2}^{\prime}\left(\hat{v}_{2}\right)}-\frac{\left[1-F_{1}\left(\hat{v}_{1}\right)\right]^{2}}{F_{1}^{\prime}\left(\hat{v}_{1}\right)} .
\end{aligned}
$$

These regularity conditions are analogous to the usual regularity assumption on virtual values, for which the monotone hazard rate property is a sufficient condition. In this case, since there are two different distributions, I require a joint regularity condition on both to guarantee the existence and uniqueness of an optimal mechanism. Type $t_{1}$ 's virtual surplus expression captures the usual virtual surplus term, and also an additional term that reflects $t_{1}$ 's outside option of receiving a unit from the points program. Type $t_{2}$ 's virtual surplus also captures the usual virtual surplus term, and an additional second-order term that reflects $t_{2}$ 's effect on $t_{1}$ 's outside option (since $t_{2}$ 's purchase decision affects the residual capacity that will be allocated among $t_{1}$ types. This regularity condition is satisfied for many distributions of interest, such as power distributions or piecewise uniform distributions. The special case where $F_{1}=F_{2}$ has a natural interpretation in this model: all consumers' values are drawn from the same distribution, $F$, but type $t_{1}$ consumers can be contracted with at $\tau=1$, whereas type $t_{2}$ cannot, for example because type $t_{1}$ have purchased from the seller in the past, while type $t_{2}$ have not, or because type $t_{2}$ arrive in period 2 . With $F_{1}=F_{2}=F$ the regularity condition simplifies to

$$
\hat{v}=\frac{[1-F(\hat{v})] F(\hat{v})}{F^{\prime}(\hat{v})} .
$$

I also impose a condition on the capacity $k$, which ensures that the seller's problem is non-trivial (i.e. does not collapse to the usual static screening problem). 
Assumption 2. Assume $k \geq \mu\left[1-F_{1}\left(\hat{v}_{1}\right)\right]+(1-\mu)\left[1-F_{2}\left(\hat{v}_{2}\right)\right]$.

This assumption guarantees that the residual capacity is weakly positive (correspondingly, $\left.H\left(\hat{v}_{1}, \hat{v}_{2}\right) \geq 0\right)$, which is the case where the points program plays an interesting role in the seller's problem. If this assumption were violated because $k$ is too low, then the capacity constraint would be binding at $\tau=2$, so the buyers' outside option would be 0 and hence the seller's problem would be identical to the usual static monopoly pricing problem, with no points program. The case where the seller has some residual capacity is more interesting from an economic perspective, and also empirically more relevant to loyalty and rewards programs in practice, as they typically involve unsold capacity.

I can now characterize the optimal points mechanism at $\tau=2$.

Proposition 1. Under Assumptions 1 and 2 , the optimal mechanism at $\tau=2$ allocates a unit of the good to type- $t_{1}$ buyers iff $v_{1} \geq \hat{v}_{1}$ and to type- $t_{2}$ buyers iff $v_{2} \geq \hat{v}_{2}$, with

$$
\begin{aligned}
& \hat{v}_{1}=\frac{\left[1-F_{1}\left(\hat{v}_{1}\right)\right] F_{1}\left(\hat{v}_{1}\right)}{F_{1}^{\prime}\left(\hat{v}_{1}\right)}, \\
& \hat{v}_{2}=\frac{1-F_{2}\left(\hat{v}_{2}\right)}{F_{2}^{\prime}\left(\hat{v}_{2}\right)}-\frac{\left[1-F_{1}\left(\hat{v}_{1}\right)\right]^{2}}{F_{1}^{\prime}\left(\hat{v}_{1}\right)} .
\end{aligned}
$$

Type- $t_{1}$ buyers with $v_{1}<\hat{v}_{1}$ participate in the points lottery, while type $t_{2}$-buyers with $v_{2}<\hat{v}_{2}$ are excluded from the mechanism. The optimal prices which implement this allocation are

$$
\begin{aligned}
& p_{1}=\hat{v}_{1}\left[1-H\left(\hat{v}_{1}, \hat{v}_{2}\right)\right], \\
& p_{2}=\hat{v}_{2} .
\end{aligned}
$$

The main intuition behind this result is the following: the optimal prices $p_{1}, p_{2}$ are determined by the standard monopoly screening trade-off, plus the additional consideration that when the seller lowers $p_{1}$ on the margin, it induces more $t_{1}$ types to buy the good, which lowers $t_{1}$ 's endogenous equilibrium probability of obtaining a unit through the points lottery. Hence the value of the outside option of a type $t_{1}$ who buys at the posted price decreases, and the seller can charge a marginally higher price. Thus the seller now has an additional incentive to lower its prices and to increase the number of units sold, as that allows it to leave smaller rents to $t_{1}$ types that buy at the posted price, given the cutoff strategy that buyers play in equilibrium. This effect applies to both $t_{1}$ and $t_{2}$ buyers, and is reflected in the expressions for $t_{1}$ and $t_{2}$ 's virtual surpluses. Assumption 1 guarantees that there exist unique threshold valuations $\hat{v}_{1}, \hat{v}_{2}$, and hence a unique solution to the seller's problem.

This result shows that the ability of the seller to offer a points program leads to lower prices 
in period 2 and a larger total surplus. The endogenous outside option of the points mechanism reduces the seller's incentive to screen consumers at the interim stage. Proposition 1 suggests several hypotheses that one could test empirically, for example in the airline industry:

(i) consumers who redeem points for award seats have lower values than those who buy tickets at the posted price;

(ii) consumers who buy tickets but have the option to redeem points for award seats face lower equilibrium prices than if they did not have the option to redeem awards (e.g. when aggregate demand is high and the seller's capacity constraint binds);

(iii) when the seller's capacity constraint is not binding, equilibrium prices are decreasing in the seller's capacity (whereas absent a points program, they would be constant).

Given the sequentially optimal mechanism at $\tau=2$ found in Proposition 11. I can now also characterize the optimal price that the seller should charge at $\tau=1$ for participation in the points program, and the seller's overall profit from the 2 periods. Let $c s_{1}\left(\hat{v}_{1}\right)$ denote type $t_{1}$ 's expected interim surplus at $\tau=2$ if it participates in the points program at $\tau=1$; i.e. it faces a mechanism with a marginal valuation cutoff $\hat{v}_{1}$ and a corresponding posted price $p_{1}=\hat{v}_{1}\left[1-H\left(\hat{v}_{1}\right)\right]$. Analogously, let $\overline{c s}_{1}\left(\hat{v}_{2}\right)$ denote type $t_{1}$ 's expected interim surplus at $\tau=2$ if it does not participate in the points program at $\tau=1$, i.e. it faces a mechanism with a marginal valuation cutoff $\hat{v}_{2}$ and a corresponding posted price $p_{2}=\hat{v}_{2}$. Hence

$$
\begin{aligned}
& c s_{1}\left(\hat{v}_{1}\right)=\int_{0}^{\hat{v}_{1}} v_{1} H\left(\hat{v}_{1}, \hat{v}_{2}\right) d F_{1}\left(v_{1}\right)+\int_{\hat{v}_{1}}^{1} v_{1}-\hat{v}_{1}\left[1-H\left(\hat{v}_{1}, \hat{v}_{2}\right)\right] d F_{1}\left(v_{1}\right), \\
& \overline{c s}_{1}\left(\hat{v}_{2}\right)=\int_{\hat{v}_{2}}^{1} v_{1}-\hat{v}_{2} d F_{1}\left(v_{1}\right) .
\end{aligned}
$$

Proposition 2. The seller's optimal price for participation in the points program at $\tau=1$ is

$$
q=c s_{1}\left(\hat{v}_{1}\right)-\overline{c s}{ }_{1}\left(\hat{v}_{2}\right)
$$

and the expected total revenue from the optimal mechanism is

$$
\begin{aligned}
\pi= & \frac{\left[1-F_{1}\left(\hat{v}_{1}\right)\right]^{2}}{F_{1}^{\prime}\left(\hat{v}_{1}\right)}\left[\mu+(1-\mu)\left(1-F_{2}\left(\hat{v}_{2}\right)\right)-k\right]+ \\
& +(1-\mu)\left(1-F_{2}\left(\hat{v}_{2}\right)\right)\left[\frac{1-F_{2}\left(\hat{v}_{2}\right)}{F_{2}^{\prime}\left(\hat{v}_{2}\right)}-\frac{\left(1-F_{1}\left(\hat{v}_{1}\right)\right)^{2}}{F_{1}^{\prime}\left(\hat{v}_{1}\right)}\right]+c s_{1}\left(\hat{v}_{1}\right)-\overline{c s}_{1}\left(\hat{v}_{2}\right)
\end{aligned}
$$

The intuition for this result is that at $\tau=1$ the seller must charge a fee $q$ that induces type $t_{1}$ to participate in the points program, rather than opt out of it and mimic type $t_{2}$. The optimal fee 
is then equal to the difference between $t_{1}$ 's expected interim surplus from the two continuation games, and it leaves $t_{1}$ exactly indifferent between participating in the points mechanism and not. Hence type $t_{1}$ 's expected overall surplus is equal to $\overline{c s} s_{1}\left(\hat{v}_{2}\right) \cdot{ }^{9}$

To summarize, Propositions 1 and 2 show that the optimal points mechanism is generally more efficient than the corresponding static mechanism, as the points mechanism introduces an additional consideration for the seller, which pushes both the price $p_{1}$ and the marginal buyer valuation $\hat{v}_{1}$ downwards, compared to a static mechanism. With the points mechanism, the seller has less of an incentive to distort the allocation for type $t_{1}$ at $\tau=2$ away from the efficient one. Moreover, Proposition 2 also characterizes the buyer's expected surplus, which is analogous to that in a static mechanism. The additional surplus generated by the lower price in the points mechanism is captured by the seller, through the participation fee $q$.

\subsubsection{Discussion}

The results in Section 4.1 lead to several interesting observations about the role of the points program in the seller's pricing strategy and its effect on consumers.

First, the adoption of a points program benefits both types of consumers (compared to the usual static mechanism, discussed in more detail in section 4.2). The seller has a novel incentive at $\tau=2$ to lower both types' prices, in order to reduce the interim value of type $t_{1}$ 's outside option, i.e. to make the points program less generous. This effect differs both from the seller's incentives in a static mechanism (where the outside option is 0), and from those in a dynamic mechanism with commitment. In the latter setting, the seller would not generally want to decrease the value of the points program, as it can commit to its terms and capture the associated surplus ex ante. In contrast, with limited commitment the seller's incentive at $\tau=2$ is unambiguously to "devalue" the points program as much as possible, to capture larger intra-period rents. This sequential optimality effect, which arises due to the lack of commitment of the seller, decreases the ex ante value of the program for consumers.

Nonetheless, both types of consumers benefit from the adoption of the points program in expectation, as long as the capacity constraint does not bind (assumption 2). The seller is only able to capture type $t_{1}$ 's interim surplus relative to that type's outside option, which is to mimic type $t_{2}$. Thus $t_{1}$ 's overall expected surplus from the game is equal to $t_{2}$ 's, and both benefit from

\footnotetext{
${ }^{9}$ Notice that a type $t_{1}$ buyer may receive a negative payoff ex post, with some probability. For example, a $t_{1}$ buyer with valuation $v_{1}=0$ gets an ex post payoff of $-q$, and more generally, a low value buyer who does not buy at the posted price may similarly have a negative ex post payoff, if it does not receive a unit from the points program. However in expectation buyer types receive weakly positive payoffs and their participation is guaranteed ex interim at $\tau=1$.
} 
the seller's incentive to reduce spot prices at $\tau=2$.

Second, propositions 1 and 2 imply that the seller's profit is front-loaded: it captures less revenue at $\tau=2$ and more at $\tau=1$. This reflects the fact that the seller screens consumers less at $\tau=2$ and restricts its quantities sold to a lesser extent than in the standard monopolistic pricing model. Specifically, from Proposition 2 the seller's period 2 interim profit from type $t_{1}$ is

$$
\pi_{t_{1}} \equiv \frac{\left[1-F_{1}\left(\hat{v}_{1}\right)\right]^{2}}{F_{1}^{\prime}\left(\hat{v}_{1}\right)}\left[\mu+(1-\mu)\left(1-F_{2}\left(\hat{v}_{2}\right)\right)-k\right] .
$$

In the standard monopolistic pricing model, the corresponding revenue from type $t_{1}$ would be

$$
\pi_{t_{1}}^{M} \equiv \frac{\left[1-F_{1}\left(\bar{v}_{1}\right)\right]^{2}}{F_{1}^{\prime}\left(\bar{v}_{1}\right)} \mu
$$

The $\pi_{t_{1}}$ term is lower, since $k>(1-\mu)\left(1-F_{2}\left(\hat{v}_{2}\right)\right)$ by assumption 2 , and the corresponding virtual surplus type is smaller with the points program.

Moreover, the term $\left[\mu+(1-\mu)\left(1-F_{2}\left(\hat{v}_{2}\right)\right)-k\right]$ is exactly the measure of type $t_{1}$ buyers who do not obtain a unit of the good through either the posted price or the points program, since $k-(1-\mu)\left(1-F_{2}\left(\hat{v}_{2}\right)\right)$ is exactly the capacity that will be allocated to $t_{1}$ buyers through one of the two channels. Hence the seller's interim profit is strictly decreasing in the capacity that is allocated to type $t_{1}$ consumers (through either channel), unlike in the usual monopolistic pricing problem. Here, more capacity allocated to $t_{1}$ types leads to strictly lower interim revenue, because it requires more capacity to be allocated through the points lottery, and hence requires larger surplus for $t_{1}$ types to be induced to buy at the posted price. Nonetheless, the seller captures additional revenue at $\tau=1$, as in equilibrium it benefits from the surplus that consumers anticipate from $\tau=2$.

Similarly, the seller's period 2 profit from type $t_{2}$ is

$$
\pi_{t_{2}}=(1-\mu) \frac{\left[1-F_{2}\left(\hat{v}_{2}\right)\right]^{2}}{F_{2}^{\prime}\left(\hat{v}_{2}\right)}-(1-\mu) \frac{\left[1-F_{2}\left(\hat{v}_{2}\right)\right]\left[1-F_{1}\left(\hat{v}_{1}\right)\right]^{2}}{F_{1}^{\prime}\left(\hat{v}_{1}\right)} .
$$

In the standard monopolistic pricing model, the corresponding revenue from type $t_{2}$ would be

$$
\pi_{t_{2}}^{M} \equiv(1-\mu) \frac{\left[1-F_{2}\left(\bar{v}_{2}\right)\right]^{2}}{F_{2}^{\prime}\left(\bar{v}_{1}\right)} \text {. }
$$

The $\pi_{t_{2}}$ term is lower, since the seller can reduce $t_{1}$ 's outside option by selling more units to type $t_{2}$. This has a second-order effect on the monopolist's interim profits from type $t_{2}$, reflected in $\frac{\left[1-F_{2}\left(\hat{v}_{2}\right)\right]\left[1-F_{1}\left(\hat{v}_{1}\right)\right]^{2}}{F_{1}^{\prime}\left(\hat{v}_{1}\right)}$. 
Finally, propositions 1 and 2 show that the effect of the points program is different from that of sequential screening. In the canonical sequential screening model, the seller benefits from dynamic contracting because it allows it to screen consumers at two different stages and exploit the differences in their value distributions. Sequential screening models generally assume that different types have value distributions ordered according to first-order stochastic dominance, as in Courty and Li (2000)'s two-type model (Proposition 2.2). These differences in the distributions represent the difference between business and leisure travellers in the airline industry, for example. Hence the effect of sequential screening vanishes if the types have identical value distributions.

In contrast, in my model the effect of the points program exists even when these value distributions are exactly the same. Consider the special case where $F_{1}=F_{2}=F$, under the interpretation that $t_{1}$ types arrive at $\tau=1$ and $t_{2}$ types arrive at $\tau=2$. In this case there is no

heterogeneity among consumers at $\tau=1$, except for the ability of the seller to interact with a subset of types at $\tau=1$. From Proposition 1, the virtual surplus equation is the same for both types, and yields

$$
\hat{v}=\frac{[1-F(\hat{v})] F(\hat{v})}{F^{\prime}(\hat{v})} .
$$

Hence the allocation of the good at the posted price is the same, but the seller charges $t_{1}$ a lower price than $t_{2}$ :

$$
p_{1}=\hat{v}[1-H(\hat{v}, \hat{v})]<\hat{v}=p_{2}
$$

in order to incentivize it to buy, rather than take the points lottery.

Therefore under this interpretation the points program helps the seller screen consumers based on their arrival times, rather than based on differences in their value distributions. These differences in arrival times can be interpreted as differences in the frequency with which buyers participate in the market: the seller can interact with buyers ex ante and offer them a points program if they purchase repeatedly, but cannot interact with them if they are one-off buyers. Therefore the points program adds an additional tool to price discriminate (even in the absence of differences in value distributions), beyond the well-known monopolistic and sequential screening tools.

\subsection{The static and full commitment benchmarks}

As a benchmark for comparison I now consider the optimal mechanisms in three different settings: (i) a static model where $\tau=2$ is the only period, (ii) a static model with an ex ante participation fee, and (iii) a dynamic model with full commitment where at $\tau=1$ the seller can 
commit to a mechanism for $\tau=1,2$. These three settings are closely related to my analysis of points mechanisms, but they reflect very different assumptions regarding what is contractible or not from the perspective of $\tau=1$. The first static setting is least demanding in terms of the degree of commitment that it requires on the part of the seller, as it only requires intra-period commitment within $\tau=2$. A static setting with an ex ante participation fee, on the other hand, would require that the seller can commit to completely exclude buyer types at $\tau=2$ if they do not participate at $\tau=1$, which is not sequentially optimal. Moreover, this requires that the seller be able to interact with all buyer types at $\tau=1$, whereas my main model can be interpreted as one where the seller can interact with some subset of buyer types at $\tau=1$. Finally, a dynamic model is the most demanding on the part of the seller, as it must be able to commit to long-term contracts for all buyer types, where the period 2 prices and allocations are generally not sequentially optimal. The latter is a strong assumption that may not be realistic in many applications, such as in the airline examples of the allocation of award redemptions and business upgrades.

I compare the optimal points mechanism with limited commitment to all three of these benchmarks, in order to illustrate the main driving forces behind the different distortions that arise in these settings. Throughout the remaining analysis I assume, analogously to Assumption 1 . that the relevant distributions of valuations in each benchmark are nicely behaved, i.e. satisfy regularity conditions that yield unique solutions for the virtual valuation equations.

\section{The optimal static mechanism}

Remark 1. Consider the static model where $F_{S}(v)=\mu F_{1}(v)+(1-\mu) F_{2}(v)$ denotes the aggregate distribution of buyer valuations at $\tau=2$. The optimal static mechanism at $\tau=2$ is a posted price mechanism with $p=\hat{v}_{S}$, where $\hat{v}_{S}=\frac{1-F_{S}\left(\hat{v}_{S}\right)}{F_{S}^{\prime}\left(\hat{v}_{S}\right)}$.

The seller's expected total revenue is

$$
\pi_{S} \equiv \frac{\left[1-F_{S}\left(\hat{v}_{S}\right)\right]^{2}}{F_{S}^{\prime}\left(\hat{v}_{S}\right)}
$$

In the special case where $F_{1}=F_{2}$ it is particularly easy to compare the points mechanism and the static mechanism. In this case Proposition 1 and Remark 1 imply the following corollary.

Corollary 1. If $F_{1}=F_{2}$, then $F_{S}=F_{2}$ and $\hat{v}_{S} \geq \hat{v}_{1}=\hat{v}_{2}$. Moreover, total surplus is larger in the optimal points mechanism, the buyer's expected surplus is larger, and the seller's expected profit is larger in the optimal points mechanism, $\pi>\pi_{S}$. 
If $F_{1}=F_{2}$, the interpretation of the main model is that type $t_{1}$ arrives at $\tau=1$, or can be contracted with at $\tau=1$, whereas type $t_{2}$ either arrives later at $\tau=2$, or cannot be contracted with at $\tau=1$. In this case the seller strictly benefits from the ability to offer a points mechanism, as opposed to a static one. The prices and allocations in the optimal static mechanism generate larger total surplus than in the optimal static one. The optimal $q$ in Proposition 2 implies that the buyer's expected ex ante surplus is weakly larger than that from the static mechanism, and the seller captures all of the residual surplus. In particular, the revenue from type $t_{1}$ is front-loaded in the points mechanism: the seller captures less revenue from $t_{1}$ at $\tau=2$, but total revenue from $t_{1}$ is larger, as the fee $q$ charged at $\tau=1$ more than offsets the lower interim revenue at $\tau=2$.

\section{The optimal static mechanism with a participation fee}

One can also compare the points mechanism to a static one with a participation fee. The latter setting requires a stronger degree of commitment, as it allows the seller to commit to exclude buyer types in period $\tau=2$ if they do not pay a fee at $\tau=1$. In contrast, in the points mechanism the seller cannot credibly exclude any types at $\tau=2$, and the prices and allocations offered at $\tau=2$ have to be sequentially optimal. The optimal static mechanism with a participation fee is one where the seller sets the same price as in Remark 1 and charges a participation fee equal to the entire expected interim buyer surplus. The seller can extract all of the surplus because it can now commit to exclude any type who does not participate.

Remark 2. The optimal static mechanism with a participation fee consists of posted prices at $\tau=2$,

$$
p= \begin{cases}\hat{v}_{S} & \text { if the buyer participates at } \tau=1 \\ 1 & \text { if the buyer does not participate at } \tau=1\end{cases}
$$

and a participation fee at $\tau=1, q_{P}=\int_{\hat{v}_{S}}^{1} v-\hat{v}_{S} d F_{S}(v)$.

The seller's expected total revenue is equal to the total surplus,

$$
\pi_{P} \equiv \int_{\hat{v}_{S}}^{1} v d F_{S}(v)
$$

\section{The optimal full commitment mechanism}

In contrast to the previous two benchmarks, now consider a two-period setting with full commitment. The seller can offer a dynamic mechanism at $\tau=1$, so it can commit ex ante to 
transfers and allocations over both periods. This setting is the same as the two-type case of Courty and $\mathrm{Li}(2000)$, and the optimal mechanism is characterized by their Proposition 2.2.

It is easy to see that the points mechanism is less efficient and yields lower expected revenue than the optimal dynamic mechanism with full commitment. This is because transfers and allocations in the points mechanism have to be sequentially optimal at $\tau=2$, when the buyer already has more precise private information about her type. In contrast, in the dynamic mechanism this sequential optimality consideration is absent, and the seller internalizes the efficiency gains from the transfers and allocations it induces at $\tau=2$, because it can capture those gains in expectation, at $\tau=1$.

To see that the total surplus and the seller's expected profits are larger in the full commitment mechanism than in the points mechanism, consider the following (suboptimal) dynamic mechanism that the seller could commit to.

Remark 3. Consider a dynamic mechanism with posted prices $p_{1}=0, p_{2}=\hat{v}_{2}$, for types $t_{1}, t_{2}$ respectively, and a participation fee of $q=c s_{1}(0)-\overline{c s}_{1}\left(\hat{v}_{2}\right)$. This mechanism yields larger revenue and generates larger total surplus than the optimal points mechanism.

More generally, the optimal dynamic mechanism does weakly better than that in Remark 3, as the seller would offer a different price $p_{2}$ which reduces type $t_{1}$ 's information rents. Hence full commitment would be more valuable to the seller than the ability to offer a points program. The latter, however, requires a weaker and more realistic degree of commitment in many settings.

\subsection{Points mechanisms without commitment}

A natural question in this setting is how important is the precise type of commitment that the seller can make in period 1 regarding its points program. As an alternative assumption, suppose the seller cannot commit to allocate all unsold capacity through the points program, but instead chooses how much of this unsold capacity to allocate, in a sequentially rational manner. What equilibria can be sustained in this case, and what revenue can the seller capture?

To answer this question I first have to slightly generalize the timing of the events in the model. In period 1 the seller offers a points program; buyers privately learn their type $t_{i}$ and decide whether to participate in the points program. In period 2 buyers privately learn their valuations; the seller posts a price for the good and the buyers simultaneously decide whether to buy a unit or not. Finally, the seller decides what measure of its unsold capacity to allocate through the points program. This timing of the model simply adds an additional stage at the end, where 
the seller chooses ex post how much of its unsold capacity to give away. As in the main model, I focus on the equilibrium where types $t_{1}$ participate in the points program while $t_{2}$ do not.

I denote by $r$ the measure of the good that the seller decides to give away ex post, where

$$
r \in\left[0, k-d\left(p_{1}, p_{2}\right)\right]
$$

and $d\left(p_{1}, p_{2}\right)$ is the measure of the good sold at $\tau=2$, in the equilibrium where type $t_{1}$ participates in the points program at $\tau=1$ and $t_{2}$ does not participate.

The following proposition shows that this extension of the model has a continuum of equilibria with different allocations and different buyer beliefs regarding the seller's unsold capacity. The set of equilibria spans the full range of mechanisms between the static mechanism in Remark 1 and the optimal points mechanism with limited commitment in Proposition 2. At one extreme, there is an equilibrium where ex post the seller allocates no residual capacity through the points program, i.e. $r=0$; buyers anticipate this and make purchase decisions as if there is no points program; this mimics the optimal static mechanism. At the other extreme, there is an equilibrium where the seller allocates all of its residual capacity through the points program, i.e. $r=k-d\left(p_{1}, p_{2}\right)$; buyers anticipate this and make purchase decisions as if the seller has commitment; this mimics the optimal points mechanism.

Proposition 3. Under Assumption 1, the extension of the model where the seller chooses $r$ ex post has a continuum of equilibria. For $r \in\left[0, k-\mu\left(1-F\left(\hat{v}_{1}\right)\right)-(1-\mu)\left(1-F\left(\hat{v}_{2}\right)\right)\right]$ there exists an equilbirium with price $p_{1}^{r}$ for type $t_{1}$ given by:

$$
p_{1}^{r} \in\left[p_{1}, \bar{p}_{1}\right]
$$

where $p_{1}=\frac{\left(1-F_{1}\left(\hat{v}_{1}\right)\right)}{F_{1}^{\prime}\left(\hat{v}_{1}\right)}\left[\mu-k+(1-\mu)\left(1-F_{2}\left(\hat{v}_{2}\right)\right)\right], \bar{p}_{1}=\frac{1-F_{1}\left(\bar{v}_{1}\right)}{F_{1}^{\prime}\left(\bar{v}_{1}\right)}$, and $\hat{v}_{1}$ and $\bar{v}_{1}$ solve:

$$
\hat{v}_{1}=\frac{\left[1-F_{1}\left(\hat{v}_{1}\right)\right]\left[F_{1}\left(\hat{v}_{1}\right)\right]}{F_{1}^{\prime}\left(\hat{v}_{1}\right)} \quad \text { and } \quad \bar{v}_{1}=\frac{1-F_{1}\left(\bar{v}_{1}\right)}{F_{1}^{\prime}\left(\bar{v}_{1}\right)}
$$

The revenue-maximal equilibrium, which is weakly Pareto dominant, coincides with the optimal points mechanism and has:

$p_{1}^{r}=\frac{\left(1-F_{1}\left(\hat{v}_{1}\right)\right)}{F_{1}^{\prime}\left(\hat{v}_{1}\right)}\left[\mu-k+(1-\mu)\left(1-F_{2}\left(\hat{v}_{2}\right)\right)\right] \quad$ and $\quad r=k-\mu\left(1-F_{1}\left(\hat{v}_{1}\right)-(1-\mu)\left(1-F_{2}\left(\hat{v}_{2}\right)\right)\right.$.

Intuitively, when the seller chooses how much of its unsold capacity to give away ex post, it is indifferent among all feasible $r$ because there is no renegotiation at that point. This generates a 
multiplicity of equilibria, depending on which $r$ the seller chooses at the final stage of the game. In each equilibrium the buyer correctly anticipates the seller's choice of $r$. For any $r$ a buyer of type $t_{1}$ must then play a cutoff strategy when deciding whether to buy a unit or not, with the cutoff $v_{1}^{r}\left(p_{1}\right)$ depending on her belief about $r$ and on the posted price $p_{1}$. Given this, the seller chooses $p_{1}$ to maximize its revenue, anticipating that the buyer will decide according to the cutoff strategy $v_{1}^{r}\left(p_{1}\right)$. Different equilibrium values of $r$ determine different equilibrium prices

$p_{1}^{r}$, ranging between the price $p_{1}=\hat{v}_{1}\left[1-H\left(\hat{v}_{1}, \hat{v}_{2}\right)\right]$ from Proposition 2, and the optimal static price $\bar{p}_{1}=\bar{v}_{1}$. Hence any outcome that is inbetween the outcomes of the points mechanism and of the static mechanism can be an equilibrium outcome.

Moreover, one can rank all of these equilibria: the revenue-maximal equilibrium is the one where $p_{1}^{r}=p_{1}$, and the seller allocates all unsold capacity through the points program, i.e. $r$ is as large as possible. This is because in all equilibria of the game the buyer has the same expected surplus, while the seller captures all of the incremental surplus that is generated by any capacity allocated through the points program. Thus the revenue-maximal equilibrium is the one that generates the largest total surplus, subject to prices being sequentially optimal at $\tau=2$. Hence the seller is better off in the equilibrium where $p_{1}^{r}$ is as low as possible, given that it is in the set $\left[p_{1}, \bar{p}_{1}\right]$, and $r$ is as large as possible, given $p_{1}^{r}$.

\subsection{Points mechanisms with uniform pricing}

In my main model the seller faces a continuum of small buyers who have private information in both periods. In period 2 the seller faces 2 subsets of buyers with valuations drawn from two different distributions, so the seller benefits from price discrimination at $\tau=2$. In this section, I instead consider a model with a continuum of infinitesimal representative buyers, whose private valuations are drawn from the same distribution, and characterize the optimal points mechanism with uniform pricing at $\tau=2$, i.e. when the seller does not price discriminate in the spot market. As before, I study the equilibrium where type $t_{1}$ participates in the points program, while type $t_{2}$ does not. In what follows I present assumptions and results that closely mirror those in section 4.1

Consider a seller with capacity $k<1$ who faces a continuum of buyers with measure 1 , each buyer with a unit demand for the good. As in the main model, the seller and buyers interact over 2 periods, $\tau \in\{1,2\}$. At $\tau=1$ all buyers have type $t=t_{1}$ with probability $\mu$, or $t=t_{2}$ with probability $1-\mu$. Each type $t_{i}$ in period 1 corresponds to a distribution over the buyers' valuations realized in period 2: type $t_{1}$ has $v$ drawn from some distribution $F_{1}$, while 
type $t_{2}$ has $v$ drawn from some distribution $F_{2} \cdot 10$ As in the main model the distribution of values is uncertain at $\tau=1$, representing the heterogeneity of buyers in the spot market. The only difference here is that values are drawn from a single distribution at $\tau=2$, so there is a continuum of representative buyers.

Lemma 2. Let

$$
H\left(\bar{v}_{1}\right) \equiv \frac{k-\left[1-F_{1}\left(\bar{v}_{1}\right)\right]}{F_{1}\left(\bar{v}_{1}\right)}
$$

denote a type $t_{1}$ buyer's endogenous probability of receiving a unit from the points program, when the marginal $t_{1}$ buyer type at $\tau=2$ is $\bar{v}_{1}$.

Then the seller's expected profit from $\tau=2$ can be written as:

$$
\max _{\bar{v}_{1}} \quad \bar{v}_{1}\left[1-H\left(\bar{v}_{1}\right)\right]\left[1-F_{1}\left(\bar{v}_{1}\right)\right] \mu \quad+\quad \bar{v}_{2}\left[1-F_{2}\left(\bar{v}_{2}\right)\right](1-\mu)
$$

The function $H\left(\bar{v}_{1}\right)$ is the analog of $H\left(\bar{v}_{1}, \bar{v}_{2}\right)$ defined previously, and captures type $t_{1}$ 's endogenous outside option, which in this case is independent of the prices and allocations offered to type $t_{2}$.

To guarantee the existence and uniqueness of an optimal mechanism, I impose the following modified regularity condition on the distributions of values, $F_{1}$ and $F_{2}$.

Assumption 3. Assume that there exist unique $\hat{v}_{1}, \hat{v}_{2}$ with $\hat{v}_{1} \leq \hat{v}_{2}$ such that the value distributions $F_{1}$ and $F_{2}$ satisfy the following conditions:

$$
\begin{aligned}
& \hat{v}_{1}=\frac{\left[1-F_{1}\left(\hat{v}_{1}\right)\right] F_{1}\left(\hat{v}_{1}\right)}{F_{1}^{\prime}\left(\hat{v}_{1}\right)} \\
& \hat{v}_{2}=\frac{1-F_{2}\left(\hat{v}_{2}\right)}{F_{2}^{\prime}\left(\hat{v}_{2}\right)}
\end{aligned}
$$

This joint regularity condition is analogous to Assumption 1, the only difference being that type $t_{2}$ 's virtual surplus is now independent of $t_{1}$ 's virtual surplus, since the two types do not interact in period 2. Hence $t_{2}$ 's virtual surplus is exactly the same as in a static model.

I also impose an analogous condition on the capacity $k$, which ensures that the seller's problem is non-trivial (i.e. does not collapse to the usual static screening problem).

Assumption 4. Assume $k \geq 1-F_{1}\left(\hat{v}_{1}\right)$.

I can now characterize the optimal points mechanism with uniform pricing at $\tau=2$.

\footnotetext{
${ }^{10}$ Equivalently, there is a state of the world $t \in\left\{t_{1}, t_{2}\right\}$, with corresponding probabilities $\mu$ and $1-\mu$, and in state $t_{1}$ the valuations are drawn from $F_{1}$, while in state $t_{2}$ they are drawn from $F_{2}$.
} 
Proposition 4. Under Assumptions 3 and 4, the optimal points mechanism at $\tau=2$ allocates a unit of the good to type- $t_{1}$ buyers iff $v_{1} \geq \hat{v}_{1}$ and to type- $t_{2}$ buyers iff $v_{2} \geq \hat{v}_{2}$, with

$$
\begin{aligned}
& \hat{v}_{1}=\frac{\left[1-F_{1}\left(\hat{v}_{1}\right)\right] F_{1}\left(\hat{v}_{1}\right)}{F_{1}^{\prime}\left(\hat{v}_{1}\right)}, \\
& \hat{v}_{2}=\frac{1-F_{2}\left(\hat{v}_{2}\right)}{F_{2}^{\prime}\left(\hat{v}_{2}\right)} .
\end{aligned}
$$

Type- $t_{1}$ buyers with $v_{1}<\hat{v}_{1}$ participate in the points lottery, while type $t_{2}$-buyers with $v_{2}<\hat{v}_{2}$ are excluded from the mechanism. The optimal prices which implement this allocation are

$$
\begin{aligned}
& p_{1}=\hat{v}_{1}\left[1-H\left(\hat{v}_{1}\right)\right], \\
& p_{2}=\hat{v}_{2} .
\end{aligned}
$$

The main intuition behind this result is exactly the same as in Proposition 1 the seller's tradeoff includes the usual monopolistic screening incentives, plus the additional consideration that by lowering $t_{1}$ 's price, it can reduce $t_{1}$ 's endogenous outside option and information rents, and hence extract more surplus on the margin. The difference in this case is that with uniform pricing at $\tau=2$, this effect applies only to $t_{1}$, since the two types do not interact at $\tau=2$.

Next, I give the analog of Proposition 2. Let $c s_{1}\left(\hat{v}_{1}\right)$ denote type $t_{1}$ 's expected interim surplus at $\tau=2$ if it participates in the points program at $\tau=1$, and let $\overline{c s} s_{1}\left(\hat{v}_{1}\right)$ denote $t_{1}$ 's expected interim surplus at $\tau=2$ if it does not. Hence

$$
\begin{aligned}
& c s_{1}\left(\hat{v}_{1}\right)=\int_{0}^{\hat{v}_{1}} v_{1} H\left(\hat{v}_{1}\right) d F_{1}\left(v_{1}\right)+\int_{\hat{v}_{1}}^{1} v_{1}-\hat{v}_{1}\left[1-H\left(\hat{v}_{1}\right)\right] d F_{1}\left(v_{1}\right), \\
& \overline{c s_{1}}\left(\hat{v}_{1}\right)=\int_{\hat{v}_{1}\left[1-H\left(\hat{v}_{1}\right)\right]}^{1} v_{1}-\hat{v}_{1}\left[1-H\left(\hat{v}_{1}\right)\right] d F_{1}\left(v_{1}\right) .
\end{aligned}
$$

Proposition 5. The seller's optimal price for participation in the points program at $\tau=1$ is

$$
q=c s_{1}\left(\hat{v}_{1}\right)-\bar{c} s_{1}\left(\hat{v}_{1}\right)
$$

and the expected total revenue from the optimal mechanism is

$$
\pi=\mu \frac{\left[1-F_{1}\left(\hat{v}_{1}\right)\right]^{2}(1-k)}{F_{1}^{\prime}\left(\hat{v}_{1}\right)}+(1-\mu) \frac{\left[1-F_{2}\left(\hat{v}_{2}\right)\right]^{2}}{F_{2}^{\prime}\left(\hat{v}_{2}\right)}+c s_{1}\left(\hat{v}_{1}\right)-\overline{c s}{ }_{1}\left(\hat{v}_{1}\right)
$$

Proposition 5 shows that the main results also hold with uniform pricing at $\tau=2$. The seller benefits from the ability to offer a points program, which generates lower prices and larger 
surplus at $\tau=2$, some of which is captured by the seller through the participation fee $q$ charged at $\tau=1$. The only difference relative to Proposition 2 is that the interim profits from types $t_{1}$ and $t_{2}$ are now independent, since the seller does not price discriminate in period 2.

\section{Conclusion}

This paper studies a novel aspect of points programs, such as frequent flyer and other reward programs: points programs offer firms an additional channel to implement dynamic pricing, and can be profitable even in the absence of competition. While the economics literature has generally focused on the role of points programs in creating customer loyalty and switching costs, I show that points programs are also a valuable sequential screening tool. In particular, a firm can use its points program as a way to indirectly allocate its capacity dynamically, before consumers have private information regarding their valuation for the good. This mechanism works even in the absence of commitment, i.e. even if the seller cannot fully commit as to what kind of mechanism or contract it will subsequently offer in the spot market for the good.

I study a setting where a firm can offer consumers the ability to participate in a points program ex ante, and can commit to allocate any residual unsold capacity through this program. I characterize the optimal points mechanism, where the firm sells points ex ante, it then offers a contract to sell the good to consumers who have private information about their valuations, and finally any unsold capacity is allocated among members of the points program. The introduction of the points program creates an endogenous and type-dependent outside option for consumers at the interim stage, in the spot market for the good. This changes the firm's pricing incentives, in a way that induces less screening at that stage, and hence a more efficient allocation.

The model yields new insights regarding the management and design of reward programs: I show that the optimal mechanism reverses the standard intuition of demand cannibalization. In general one might expect that if the firm offers consumers two different channels to obtain the good, the introduction of the points program may cannibalize some of the demand in the spot market for the good. This is only partially true - for any given contract, demand in the spot market is indeed lower when the firm offers a points program, since some consumers optimally choose to not purchase, and instead obtain the good through the points mechanism. However, the optimal equilibrium contract changes when the firm offers a points program. In fact, I show that the firm will set lower prices in the game where it also offers a points mechanism. Hence overall we see the opposite of demand cannibalization: by offering a points program, the firm induces more efficient pricing in the spot market, and ultimately screens less and sells more of 
its capacity. The above is also relevant to the application of antitrust and consumer protection regulation: if loyalty programs work solely as a switching cost mechanism, they can lower total surplus and reduce welfare. In contrast, my paper shows that if such programs are used to allocate unsold capacity, they can in fact increase total surplus and welfare.

The predictions of this model are consistent with several important observations from industries that feature loyalty and points programs. First, firms tend to use their loyalty programs as a way to allocate unsold capacity, or "distressed inventory." This is often noted by industry commentators who observe that airlines, for example, tend to release much of their unsold seats to members of their frequent flyer programs, who can book these seats by redeeming frequent flyer miles. Second, in addition to using pricing algorithms to implement revenue management, in practice airlines also use algorithms to decide how much capacity to release to members of their loyalty programs, and at what time to do so. The design of such algorithms is clearly an important economic problem, because the firm faces a trade-off between its pricing mechanism and its points program. Third, firms generally face a commitment problem in terms of the operation of their loyalty program: when deciding what prices to set, the firm would myopically prefer to make this program less generous, although in the long run this would undermine the value of the program and the premium that consumers would be willing to pay to participate in it. This paper shows that while loyalty programs can still be valuable in a setting with limited commitment, they would indeed be even more valuable if the firm could commit to the terms of its loyalty program. My results also provide some surprising implications for firm strategy: it is tempting to think of loyalty programs as a mechanism that induces demand cannibalization, but this is in fact a primary reason why they are profitable overall, and firms which use such programs in fact benefit from increasing participation and redemptions through their loyalty

program. Furthermore, the results and intuition apply more broadly to industries that share the main features of my model, where consumers have heterogeneous willingness to pay that is revealed over time, the firm has a fixed capacity to sell, and the firm can interact with consumers ex ante, or repeatedly over time, through its loyalty program.

\section{References}

Akan, Mustafa, Barış Ata, and James Dana (2015) "Revenue management by sequential screening," Journal of Economic Theory, Vol. 159, pp. 728-774.

Ata, Barış and James Dana (2015) "Price discrimination on booking time," International Journal of Industrial Organization, Vol. 43, pp. 175-181.

Aviv, Yossi and Amit Pazgal (2008) "Optimal pricing of seasonal products in the presence of 
forward-looking consumers," Manufacturing \&3 Service Operations Management, Vol. 10, pp. 339-359.

Baron, David P. and David Besanko (1984) "Regulation information in a continuing relationship," Information Economics and Policy, Vol. 1, pp. 267-302.

Battaglini, Marco and Rohit Lamba (2015) "Optimal dynamic contracting: the first-order approach and beyond," CEPR Discoussion Paper, No 10956.

Bergemann, Dirk and Juuso Välimäki (2010) "The dynamic pivot mechanism," Econometrica, Vol. 78 , pp. $771-789$.

Bester, Helmut and Roland Strausz (2001) "Contracting with imperfect commitment and the revelation principle: the single agent case," Econometrica, Vol. 69, pp. 1077-1098.

Board, Simon (2008) "Durable-goods monopoly with varying demand," Review of Economic Studies, Vol. 75, pp. 391-413.

Board, Simon and Andrzej Skrzypacz (2016) "Revenue management with forward-looking buyers," Journal of Political Economy, Vol. 124, pp. 1046-1087.

Borenstein, Severin (1992) "The evolution of U.S. airline competition," Journal of Economic Perspectives, Vol. 7, pp. 45-73.

Borenstein, Severin and Nancy Rose (1994) "Competition and price dispersion in the U.S. airline industry," Journal of Political Economy, Vol. 102, pp. 653-683.

Caminal, Ramon and Carmen Matutes (1990) "Endogenous switching costs in a duopoly model," International Journal of Industrial Organization, Vol. 8, pp. 353-373.

Courty, Pascal and Hao Li (2000) "Sequential screening," Review of Economic Studies, Vol. 67, pp. $697-717$.

Dana, James and Kevin Williams (2018) "Oligopoly Price Discrimination: The Role of Inventory Controls," Mimeo, Cowles Foundation Discussion Paper No. 2136.

Deb, Rahul and Maher Said (2014) "Dynamic screening with limited commitment," Journal of Economic Theory, Vol. 159, pp. 891-928.

Dilme, Francesc and Fei Li (2016) "Revenue management without commitment: dynamic pricing and periodic fire sales," Mimeo, University of Pennsylvania. 
Elmaghraby, Wedad and Pinar Keskinocak (2003) "Dynamic pricing in the presence of inventory considerations: research overview, current practices, and future directions," Management Science, Vol. 49, pp. 1287-1309.

Ely, Jeffrey C., Daniel F. Garrett, and Toomas Hinnosaar (2017) "Overbooking," Journal of the European Economic Association, Vol. 15, pp. 1258-1301.

Eső, Péter and Balázs Szentes (2007) "Optimal information disclosure in auctions and the handicap auction," Review of Economic Studies, Vol. 74, pp. 705-731.

(2017) "Dynamic contracting: an irrelevance theorem," Theoretical Economics, Vol. 12 , pp. 109-139.

Fudenberg, Drew and Jean Tirole (2000) "Customer poaching and brand switching," The RAND Journal of Economics, Vol. 31, pp. 634-657.

Garrett, Daniel (2016) "Intertemporal price discrimination: dynamic arrivals and changing values," American Economic Review, Vol. 106, pp. 3275-3299.

(2017) "Dynamic Mechanism Design: Dynamic Arrivals and Changing Values," Games and Economic Behavior, Vol. 104, p. 595-612.

Gershkov, Alex, Benny Moldovanu, and Philipp Strack (2018) "Revenue-Maximizing Mechanisms with Strategic Customers and Unknown, Markovian Demand," Management Science, Vol. 64, pp. 1975-2471.

Hörner, Johannes and Larry Samuelson (2011) "Managing Strategic Buyers," Journal of Political Economy, Vol. 119, pp. 379-425.

Hua, Xinyu (2007) "Strategic ex-ante contracts: rent extraction and opportunity costs," The RAND Journal of Economics, Vol. 38, pp. 786-803.

Jerath, Kinshuk, Serguei Netessine, and Senthil Veeraraghavan (2010) "Revenue management with strategic customers: Last-minute selling and opaque selling," Management Science, Vol. 56 , pp. $430-448$.

Kim, Byung Do, Mengze Shi, and Kannan Srinivasan (2001) "Reward programs and tacit collusion," Marketing Science, Vol. 20, pp. 99-120.

(2004) "Managing capacity through reward programs," Management Science, Vol. 50, pp. $503-520$. 
Lederman, Mara (2007) "Do enhancements to loyalty programs affect demand? The impact of international frequent flyer partnerships on domestic airline demand," The RAND Journal of Economics, Vol. 38, pp. 1134-1158.

(2008) "Are Frequent Flyer Programs a Cause of the 'Hub Premium'," Journal of Economics and Management Strategy, Vol. 17, pp. 35-66.

Myerson, Roger B. (1981) "Optimal auction design," Mathematics of Operations Research, Vol. 6, pp. 58-73.

Nocke, Volcker and Martin Peitz (2007) "A theory of clearance sales," Economic Journal, Vol. 117, pp. 964-990.

Öry, Aniko (2016) "Consumers on a leash: Advertised sales and intertemporal price discrimination," Cowles Foundation Discussion Papers, No 2047.

Pavan, Alessandro, Ilya Segal, and Juuso Toikka (2014) "Dynamic mechanism design: a Myersonian approach," Econometrica, Vol. 82, pp. 601-653.

Said, Maher (2012) "Auctions with dynamic populations: efficiency and revenue maximization," Journal of Economic Theory, Vol. 147, pp. 2419-2438.

Singh, Siddharth, Dipak Jain, and Trichy Krishnan (2008) "Research note - Customer loyalty programs: are they profitable?" Management Science, Vol. 54, pp. 1205-1211.

Skreta, Vasiliki (2006) "Sequentially optimal mechanisms," Review of Economic Studies, Vol. 73, pp. 1085-1111.

(2015) "Optimal auction design under non-commitment," Journal of Economic Theory, Vol. 159, pp. 854-890.

Stole, Lars A. (2007) "Price discrimination in competitive environments," in Mark Armstrong and Robert H. Porter eds. Handbook of Industrial Organization, Vol. 3, North-Holland, Amsterdam.

\section{Appendix}

\section{Lemma 1}

Proof. At any posted price $p_{i}$ for type $t_{i}$, if a buyer with value $v_{i}$ buys a unit at price $p_{i}$, then any type $v_{i}^{\prime}>v_{i}$ is also willing to buy a unit; if a buyer with value $v_{i}$ does not buy a unit at price 
$p_{i}$, any type $v_{i}^{\prime}<v_{i}$ is also not willing to buy a unit. Hence there exists a cutoff type, denoted $\bar{v}_{i}$, who is exactly indifferent between buying at the posted price $p_{i}$ or taking the outside option. The residual capacity of the seller is then

$$
k-\mu\left[1-F_{1}\left(\bar{v}_{1}\right)\right]-(1-\mu)\left[1-F_{2}\left(\hat{v}_{2}\right)\right] .
$$

The measure of type $t_{1}$ buyers who participate in the points program and do not buy a unit at price $p_{1}$ is $\mu F_{1}\left(\bar{v}_{1}\right)$. Hence a type $t_{1}$ buyer's probability of receiving a unit from the points program, as a function of the marginal buyer valuations, is:

$$
H\left(\bar{v}_{1}, \bar{v}_{2}\right) \equiv \frac{k-\mu\left[1-F_{1}\left(\bar{v}_{1}\right)\right]-(1-\mu)\left[1-F_{2}\left(\hat{v}_{2}\right)\right]}{\mu F_{1}\left(\bar{v}_{1}\right)} .
$$

Next, consider the buyers' equilibrium purchase decisions. For type $t_{2}$ buyers with an outside option of 0 , we have

$$
\bar{v}_{2}=p_{2}
$$

For type $t_{1}$ buyers, the marginal valuation must satisfy the indifference condition:

$$
\bar{v}_{1}-p_{1}=\bar{v}_{1} H\left(\bar{v}_{1}, \bar{v}_{2}\right) .
$$

Hence $\bar{v}_{1} \cdot\left[1-H\left(\bar{v}_{1}, \bar{v}_{2}\right)\right]=p_{1}$.

The seller's expected profit from period 2 can now be written as follows:

$$
\bar{v}_{1}\left[1-H\left(\bar{v}_{1}, \bar{v}_{2}\right)\right]\left[1-F_{1}\left(\bar{v}_{1}\right)\right] \mu \quad+\quad \bar{v}_{2}\left[1-F_{2}\left(\bar{v}_{2}\right)\right](1-\mu) .
$$

\section{Proposition 1}

Proof. By Lemma 1 the seller's maximization at $\tau=2$ is

$$
\max _{\bar{v}_{1}, \bar{v}_{2}} \quad \bar{v}_{1}\left[1-H\left(\bar{v}_{1}, \bar{v}_{2}\right)\right]\left[1-F_{1}\left(\bar{v}_{1}\right)\right] \mu+\bar{v}_{2}\left[1-F_{2}\left(\bar{v}_{2}\right)\right](1-\mu)
$$

The FOCs for $\bar{v}_{1}$ and $\bar{v}_{2}$ give the following two conditions:

$$
\begin{array}{r}
{\left[1-H\left(\bar{v}_{1}, \bar{v}_{2}\right)\right]\left[1-F_{1}\left(\bar{v}_{1}\right)\right]-F_{1}^{\prime}\left(\bar{v}_{1}\right) \bar{v}_{1}\left[1-H\left(\bar{v}_{1}, \bar{v}_{2}\right)\right]-\frac{\partial H\left(\bar{v}_{1}, \bar{v}_{2}\right)}{\partial v_{1}} \bar{v}_{1}\left[1-F_{1}\left(\bar{v}_{1}\right)\right]=0} \\
-\frac{\partial H\left(\bar{v}_{1}, \bar{v}_{2}\right)}{\partial v_{2}} \bar{v}_{1}\left[1-F_{1}\left(\bar{v}_{1}\right)\right] \mu+\left[1-F_{2}\left(\bar{v}_{2}\right)\right](1-\mu)-\bar{v}_{2} F_{2}^{\prime}\left(\bar{v}_{2}\right)(1-\mu)=0
\end{array}
$$


To simplify these, note the following:

$$
\begin{aligned}
1-H\left(\bar{v}_{1}, \bar{v}_{2}\right) & =\frac{\mu-k+(1-\mu)\left[1-F_{2}\left(\bar{v}_{2}\right)\right]}{\mu F_{1}\left(\bar{v}_{1}\right)} \\
\frac{\partial H\left(\bar{v}_{1}, \bar{v}_{2}\right)}{\partial v_{1}} & =\mu \frac{F_{1}^{\prime}\left(\bar{v}_{1}\right)}{\mu F_{1}\left(\bar{v}_{1}\right)}\left[1-H\left(\bar{v}_{1}, \bar{v}_{2}\right)\right] \\
\frac{\partial H\left(\bar{v}_{1}, \bar{v}_{2}\right)}{\partial v_{2}} & =\frac{(1-\mu) F_{2}^{\prime}\left(\bar{v}_{2}\right)}{\mu F_{1}\left(\bar{v}_{1}\right)}
\end{aligned}
$$

Hence with some re-arranging the FOCs can now be re-written as:

$$
\begin{aligned}
& \bar{v}_{1}=\frac{\left[1-F_{1}\left(\bar{v}_{1}\right)\right] F_{1}\left(\bar{v}_{1}\right)}{F_{1}^{\prime}\left(\bar{v}_{1}\right)} \\
& \bar{v}_{2}=\frac{1-F_{2}\left(\bar{v}_{2}\right)}{F_{2}^{\prime}\left(\bar{v}_{2}\right)}-\frac{\left[1-F_{1}\left(\bar{v}_{1}\right)\right]^{2}}{F_{1}^{\prime}\left(\bar{v}_{1}\right)}
\end{aligned}
$$

By Assumption 3, there exist unique $\hat{v}_{1}$ and $\hat{v}_{2}$ that solve these equations. In particular, $t_{1}$ types with values $v_{1} \geq \hat{v}_{1}$ buy a unit and those with values $v_{1}<\hat{v}_{1}$ participate in the points program; $t_{2}$ types with values $v_{2} \geq \hat{v}_{2}$ buy a unit and those with values $v_{2}<\hat{v}_{2}$ are excluded from the mechanism.

The optimal prices that correspond to this allocation are:

$$
\begin{aligned}
& p_{1}=\hat{v}_{1}\left[1-H\left(\hat{v}_{1}, \hat{v}_{2}\right)\right], \\
& p_{2}=\hat{v}_{2} .
\end{aligned}
$$

\section{Proposition 2}

Proof. At $\tau=1$ a type $t_{1}$ buyer has the option to pay the fee $q$ and participate in the points program, or not. In the former case, the buyer's expected surplus from the sequentially optimal prices at $\tau=2$, given by Proposition 1 , is equal to $c s_{1}\left(\hat{v}_{1}\right)$. If instead the buyer does not participate, type $t_{1}$ 's expected interim surplus in this case is $\overline{c s_{1}}\left(\hat{v}_{2}\right)$, corresponding to the subgame where at $\tau=2$ it faces the sequentially optimal price $p_{2}=\hat{v}_{2}$. The optimal fee $q$ is 
such that type $t_{1}$ is exactly indifferent between these two continuation games, hence

$$
\begin{aligned}
q=c s_{1}\left(\hat{v}_{1}\right)-\overline{c s} s_{1}\left(\hat{v}_{2}\right)= \\
\quad=\int_{0}^{\hat{v}_{1}} v_{1} H\left(\hat{v}_{1}\right) d F_{1}\left(v_{1}\right)+\int_{\hat{v}_{1}}^{1} v_{1}-\hat{v}_{1}\left[1-H\left(\hat{v}_{1}\right)\right] d F_{1}\left(v_{1}\right)-\int_{\hat{v}_{2}}^{1} v_{1}-\hat{v}_{2} d F_{1}\left(v_{1}\right)
\end{aligned}
$$

Therefore the seller's total expected revenue from $\tau=1,2$ is

$$
\begin{aligned}
\pi= & \frac{\left[1-F_{1}\left(\hat{v}_{1}\right)\right]^{2}}{F_{1}^{\prime}\left(\hat{v}_{1}\right)}\left[\mu+(1-\mu)\left(1-F_{2}\left(\hat{v}_{2}\right)\right)-k\right]+ \\
& +(1-\mu)\left(1-F_{2}\left(\hat{v}_{2}\right)\right)\left[\frac{1-F_{2}\left(\hat{v}_{2}\right)}{F_{2}^{\prime}\left(\hat{v}_{2}\right)}-\frac{\left(1-F_{1}\left(\hat{v}_{1}\right)\right)^{2}}{F_{1}^{\prime}\left(\hat{v}_{1}\right)}\right]+c s_{1}\left(\hat{v}_{1}\right)-\bar{c} s_{1}\left(\hat{v}_{2}\right)
\end{aligned}
$$

\section{Proposition 3}

Proof. I proceed by backward induction. Consider the seller's choice of $r$ ex post. Suppose the seller posts prices $p_{1}, p_{2}$ and a measure $d\left(p_{1}, p_{2}\right)$ of buyers purchase the good. The seller thus chooses $r \in\left[0, k-d\left(p_{1}, p_{2}\right)\right]$ ex post. Note that the seller is indifferent among all feasible $r$ at this stage. Therefore consider any equilibrium with some feasible $r \in\left[0, k-d\left(p_{1}, p_{2}\right)\right]$. When a buyer decides whether to buy a unit or not, in equilibrium she accurately anticipates $r$.

For any given equilibrium $r$, a type $t_{1}$ buyer expects some surplus $c s_{1}^{r}$ from period 2, taking as sunk the cost of participating in the points program at $\tau=1$. When the seller sets some $q^{r}$ at $\tau=1, t_{1}$ buyers choose between paying $q^{r}$ and obtaining an expected surplus of $c s_{1}^{r}$ in period 2, or not paying $q^{r}$ and obtaining a surplus of $\overline{c s}_{1}\left(\hat{v}_{2}\right)$, as in Proposition 2, The optimal price of a point, $q^{r}$, at $\tau=1$ is thus $q^{r}=c s_{1}^{r}-\overline{c s}_{1}\left(\hat{v}_{2}\right)$ for a given equilibrium $r$. Hence in any

equilibrium the consumer's expected surplus from $\tau=2$ is $\overline{c s_{1}}\left(\hat{v}_{2}\right)$, while the seller captures all of the incremental surplus generated by the points program. Thus in the revenue-maximal equilibrium, $p_{1}$ and $r$ must maximize total surplus in period 2 , subject to the constraint that the price offered is sequentially optimal.

Following the proof of Proposition 1, the sequentially optimal price for type $t_{1}$ for any $r$ at $\tau=2$ must be in the set $\left[p_{1}, \bar{p}_{1}\right]$, where

$$
p_{1}=\frac{\left(1-F_{1}\left(\hat{v}_{1}\right)\right)}{F_{1}^{\prime}\left(\hat{v}_{1}\right)}\left[\mu-k+(1-\mu)\left(1-F_{2}\left(\hat{v}_{2}\right)\right)\right] \quad \text { and } \quad \bar{p}_{1}=\frac{1-F_{1}\left(\bar{v}_{1}\right)}{F_{1}^{\prime}\left(\bar{v}_{1}\right)}
$$


and $\hat{v}_{1}$ and $\bar{v}_{1}$ solve:

$$
\hat{v}_{1}=\frac{\left[1-F_{1}\left(\hat{v}_{1}\right)\right]\left[F_{1}\left(\hat{v}_{1}\right)\right]}{F_{1}^{\prime}\left(\hat{v}_{1}\right)} \quad \text { and } \quad \bar{v}_{1}=\frac{1-F_{1}\left(\bar{v}_{1}\right)}{F_{1}^{\prime}\left(\bar{v}_{1}\right)}
$$

Notice that total surplus is maximized, subject to the constraint that $p_{1}^{r}$ be sequentially optimal, when $p_{1}^{r}$ is as small as possible, i.e. equal to $p_{1}$ in Proposition 1 , and when $r=k-\mu\left(1-F_{1}\left(\hat{v}_{1}\right)\right)-$ $(1-\mu)\left(1-F_{2}\left(\hat{v}_{2}\right)\right)$.

Therefore the revenue-maximal equilibrium is the one where:

$p_{1}^{r}=\frac{\left(1-F_{1}\left(\hat{v}_{1}\right)\right)}{F_{1}^{\prime}\left(\hat{v}_{1}\right)}\left[\mu-k+(1-\mu)\left(1-F_{2}\left(\hat{v}_{2}\right)\right)\right] \quad$ and $\quad r=k-\mu\left(1-F_{1}\left(\hat{v}_{1}\right)-(1-\mu)\left(1-F_{2}\left(\hat{v}_{2}\right)\right)\right.$.

\section{Lemma 2}

Proof. At any posted price $p_{i}$ for type $t_{i}$, if a buyer with value $v_{i}$ buys a unit at price $p_{i}$, then any type $v_{i}^{\prime}>v_{i}$ is also willing to buy a unit; if a buyer with value $v_{i}$ does not buy a unit at price $p_{i}$, any type $v_{i}^{\prime}<v_{i}$ is also not willing to buy a unit. Hence there exists a cutoff type, denoted $\bar{v}_{i}$, who is exactly indifferent between buying at the posted price $p_{i}$ or taking the outside option. In the history where the buyer participates at $\tau=1$, the seller believes $t=t_{1}$ and sets a posted price $p_{1}$, which induces some corresponding cutoff valuation $\bar{v}_{1}$. The residual capacity of the seller is then $k-\left[1-F_{1}\left(\bar{v}_{1}\right)\right]$. The measure of type $t_{1}$ buyers who participate in the points program and do not buy a unit at price $p_{1}$ is $F_{1}\left(\bar{v}_{1}\right)$. Hence a type $t_{1}$ buyer's probability of receiving a unit from the points program, as a function of the marginal buyer valuation, is:

$$
H\left(\bar{v}_{1}\right) \equiv \frac{k-\left[1-F_{1}\left(\bar{v}_{1}\right)\right]}{F_{1}\left(\bar{v}_{1}\right)} .
$$

Next, consider the buyers' equilibrium purchase decisions. For type $t_{2}$ buyers with an outside option of 0 , we have

$$
\bar{v}_{2}=p_{2}
$$

For type $t_{1}$ buyers, the marginal valuation must satisfy the indifference condition:

$$
\bar{v}_{1}-p_{1}=\bar{v}_{1} H\left(\bar{v}_{1}\right)
$$

Hence $\bar{v}_{1} \cdot\left[1-H\left(\bar{v}_{1}\right)\right]=p_{1}$. 
The seller's expected profit from period 2 can now be written as follows:

$$
\bar{v}_{1}\left[1-H\left(\bar{v}_{1}\right)\right]\left[1-F_{1}\left(\bar{v}_{1}\right)\right] \mu \quad+\quad \bar{v}_{2}\left[1-F_{2}\left(\bar{v}_{2}\right)\right](1-\mu) .
$$

\section{Proposition 4}

Proof. By Lemma 2 the seller's maximization at $\tau=2$ is

$$
\max _{\bar{v}_{1}, \bar{v}_{2}} \quad \bar{v}_{1}\left[1-H\left(\bar{v}_{1}\right)\right]\left[1-F_{1}\left(\bar{v}_{1}\right)\right] \mu \quad+\quad \bar{v}_{2}\left[1-F_{2}\left(\bar{v}_{2}\right)\right](1-\mu) .
$$

The FOCs for $\bar{v}_{1}$ and $\bar{v}_{2}$ give the following two conditions:

$$
\begin{aligned}
{\left[1-H\left(\bar{v}_{1}\right)\right]\left[1-F_{1}\left(\bar{v}_{1}\right)\right]-F_{1}^{\prime}\left(\bar{v}_{1}\right) \bar{v}_{1}\left[1-H\left(\bar{v}_{1}\right)\right]-H^{\prime}\left(\bar{v}_{1}\right) \bar{v}_{1}\left[1-F_{1}\left(\bar{v}_{1}\right)\right] } & =0 \\
1-F_{2}\left(\bar{v}_{2}\right)-F_{2}^{\prime}\left(\bar{v}_{2}\right) \bar{v}_{2} & =0
\end{aligned}
$$

To simplify these, note the following:

$$
\begin{aligned}
1-H\left(\bar{v}_{1}\right) & =\frac{1-k}{F_{1}\left(\bar{v}_{1}\right)} \\
H^{\prime}\left(\bar{v}_{1}\right) & =\frac{F_{1}^{\prime}\left(\bar{v}_{1}\right)}{F_{1}\left(\bar{v}_{1}\right)}\left[1-H\left(\bar{v}_{1}\right)\right]
\end{aligned}
$$

With some re-arranging the FOCs can now be re-written as:

$$
\begin{aligned}
& \bar{v}_{1}=\frac{\left[1-F_{1}\left(\bar{v}_{1}\right)\right] F_{1}\left(\bar{v}_{1}\right)}{F_{1}^{\prime}\left(\bar{v}_{1}\right)} \\
& \bar{v}_{2}=\frac{1-F_{2}\left(\bar{v}_{2}\right)}{F_{2}^{\prime}\left(\bar{v}_{2}\right)}
\end{aligned}
$$

By Assumption 3, there exist unique $\hat{v}_{1}$ and $\hat{v}_{2}$ that solve these equations. In particular, $t_{1}$ types with values $v_{1} \geq \hat{v}_{1}$ buy a unit and those with values $v_{1}<\hat{v}_{1}$ participate in the points program; $t_{2}$ types with values $v_{2} \geq \hat{v}_{2}$ buy a unit and those with values $v_{2}<\hat{v}_{2}$ are excluded from the mechanism. 
The optimal prices that correspond to this allocation are:

$$
\begin{aligned}
& p_{1}=\hat{v}_{1}\left[1-H\left(\hat{v}_{1}\right)\right]=\frac{\left[1-F_{1}\left(\hat{v}_{1}\right)\right](1-k)}{F_{1}^{\prime}\left(\hat{v}_{1}\right)} \\
& p_{2}=\hat{v}_{2}=\frac{\left[1-F_{2}\left(\hat{v}_{2}\right)\right]}{F_{2}^{\prime}\left(\hat{v}_{2}\right)}
\end{aligned}
$$

\section{Proposition 5}

Proof. At $\tau=1$ a type $t_{1}$ buyer has the option to pay some fee $q$ and participate in the points program, or not. In the former case, the buyer's expected surplus from the sequentially optimal mechanism at $\tau=2$, given by Proposition 4 , is equal to $c s_{1}\left(\hat{v}_{1}\right)$. If instead the buyer does not participate, type $t_{1}$ 's expected interim surplus in this case is $\overline{c s_{1}}\left(\hat{v}_{1}\right)$. The optimal fee $q$ is such that type $t_{1}$ is exactly indifferent between these two continuation games, hence

$$
\begin{gathered}
q=c s_{1}\left(\hat{v}_{1}\right)-\overline{c s_{1}}\left(\hat{v}_{1}\right)=\int_{0}^{\hat{v}_{1}} v_{1} H\left(\hat{v}_{1}\right) d F_{1}\left(v_{1}\right)+\int_{\hat{v}_{1}}^{1} v_{1}-\hat{v}_{1}\left[1-H\left(\hat{v}_{1}\right)\right] d F_{1}\left(v_{1}\right) \\
-\int_{\hat{v}_{1}\left[1-H\left(\hat{v}_{1}\right)\right]}^{1} v_{1}-\hat{v}_{1}\left[1-H\left(\hat{v}_{1}\right)\right] d F_{1}\left(v_{1}\right)
\end{gathered}
$$

Therefore the seller's total expected revenue from $\tau=1,2$ is

$$
\pi=\mu \frac{\left[1-F_{1}\left(\hat{v}_{1}\right)\right]^{2}(1-k)}{F_{1}^{\prime}\left(\hat{v}_{1}\right)}+(1-\mu) \frac{\left[1-F_{2}\left(\hat{v}_{2}\right)\right]^{2}}{F_{2}^{\prime}\left(\hat{v}_{2}\right)}+c s_{1}\left(\hat{v}_{1}\right)-\overline{c s}{ }_{1}\left(\hat{v}_{1}\right)
$$

